\title{
SEISMIC ATTRIBUTES AIDED DETECTION OF NW-SE TRENDING FAULTS DEVELOPED ON AN ISOLATED CARBONATE PLATFORM IN THE NW SIRTE BASIN, NORTH CENTRAL LIBYA
}

\author{
Muneer Abdalla \\ Department of Geology \\ Omar Al-Mukhtar University, Al Bayda 919, Libya
}

\begin{abstract}
The lower and upper Paleocene reservoir formations, the primary producing formations in the northwest Sirte Basin, north-central Libya have complex structures which have an impact on the performance of the reservoirs. It is extremely crucial to understand the complex relationships between the fault networks and stratigraphy of the area for future field development. However, delineating faults particularly subtle faults is not an easy process due to the low signal-to-noise ratio in the post stack seismic data despite the effort and careful process of the pre-stack data. Seismic attributes are critical tools in detecting and enhancing major and minor fault interpretation beyond the seismic resolution of the conventional seismic dataset. This study utilizes variance, root mean square, and curvature attributes computed from the post-stack 3D seismic data acquired in the northwest Sirte Basin to detect major and minor faults along an isolated carbonate platform. A spectral whitening and median filter were applied to improve the quality of the data and remove random noise resulted from data acquisition and processing steps. Those methods were utilized to provide high-resolution seismic data and better show edges and structural features. Numerous faults have been detected in the study area. Most major faults in the lower and upper Paleocene reservoir formations are located along the margins of the isolated carbonate platform and have a NW-SE trend. Data conditioning and seismic attribute analyses applied on the 3-D seismic dataset effectively enhanced our understanding of the reservoir complexity and improve the detection of the major and minor faults and fracture zones in the study area.
\end{abstract}

Keywords - Data conditioning, Seismic attributes, Faults, Isolated carbonate platform, Sirte Basin

\section{INTRODUCTION}

The Sirte Basin, in the north-central Libya, is the youngest, largest, and most productive petroliferous basin in Africa (Fig. 1). It is ranked as the 13th among the world's largest hydrocarbon basins, with proven reserves exceeding 43.1 billion barrels of oil equivalent (Ahlbrandt, 2002). The basin covers an area of $\sim 600,000 \mathrm{~km}^{2}, \sim 230,000 \mathrm{~km}^{2}$ of which potentially contain oil and gas accumulations. Thickness of the sedimentary successions of Sirte Basin ranges from $\sim 7 \mathrm{~km}$ offshore in the northern Gulf of Sirte to $1 \mathrm{~km}$ near the Nubian (also known as Tibesti) Uplift in the south. The Sirte Basin was formed as a result of large-scale extension that resulted in major subsidence and block faulting during the Early Cretaceous to Early Tertiary (Guiraud and Bosworth, 1997; Hallett, 2002). The main structural features within the Sirte Basin are from east to west: Maragh Trough, Hameimat Trough, Agedabia Trough, Sarir Trough, Hagfa Trough, Bu Tamaym Trough, Zellah Trough, Dor El Abida Trough, and Hun Trough. The platforms that separate the troughs are from east to west: Amal Platform, Rakb High, Messlah High, Zelten Platform, Jahama Platform, Beda Platform, Dahra Platform, and Waddan Uplift (Figs. 1b, 2; Harding, 1984; Roohi, 1996; Gras and Thusu, 1998; Ambrose, 2000).

The study area is located in the west Mabruk Field of the NW Sirte Basin (Fig. 1). The field contains a NW-SE oriented isolated carbonate platform that initiated during the early Paleocene and terminated during the early Eocene as a result of a subaerial exposure (Abdalla and Yang, 2020). The west Mabruk isolated platform covers an area of approximately $112.8 \mathrm{~km}^{2}$ and contains numerous NW-SE trending faults formed particularly along the platform margins with minor faults cut into the interior of the platform. This faulting associated with the rifting of the basin has a significant effect in reservoir producing and efficiency. The faults are thought to impact the distribution and thickness of the primary producing 


\section{International Journal of Engineering Applied Sciences and Technology, 2021 \\ Vol. 5, Issue 11, ISSN No. 2455-2143, Pages 53-56 \\ Published Online March 2021 in IJEAST (http://www.ijeast.com)}

Paleocene Mabruk Formation. Understanding the relationships between the fault network and stratigraphy of the area is extremely crucial for future field development. Therefore, this study utilizes seismic attributes in order to reveal major and minor faults hidden in seismic data. Among hundreds of seismic attributes developed, variance-based-coherence and curvature are believed to be the most powerful attributes in the interpretation of structural discontinuities. The aim of this study is to delineate the faults systematically in the west Mabruk Field in the NW Sirte Basin and to understand their relationship to the reservoir formations.

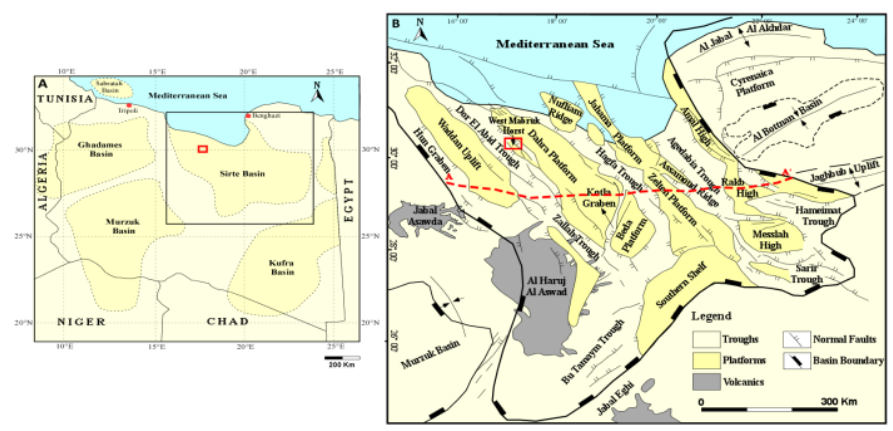

Fig. 1. (a) A map showing the major sedimentary basins in Libya. (b) A structural map of the Sirte Basin in north-central Libya showing the major structural elements (modified after Mouzughi and Taleb, 1981). The black box is the location of b. The study area is marked by the red square box.

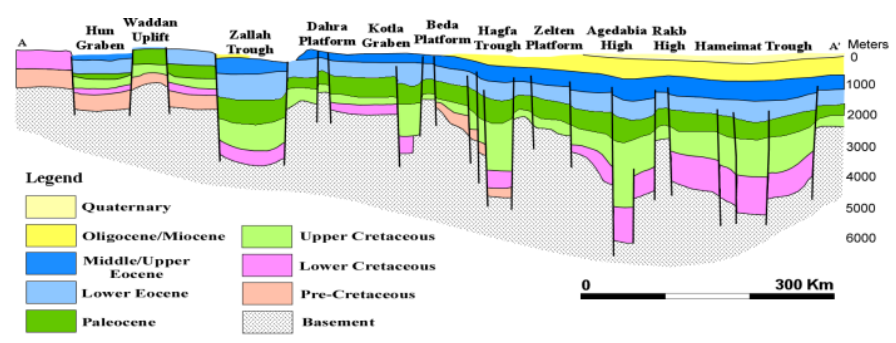

Fig. 2. E-W structural cross-section showing major structural features across the Sirte Basin (modified after Roohi, 1996a). Location of the cross section is shown by the red dashed line in Fig. 1. Notice that most of the normal faults related to rifting terminate in the lower Eocene strata, suggesting that rifting may have ended during the early Eocene. Location of cross-section is shown on Fig. $1 b$.

\section{DATA, METHODOLOGY, AND RESULTS}

The dataset used in this study includes a 3-D post-stack seismic volume that covers an area of approximately 112.8 $\mathrm{km}^{2}$, and have $25 \times 25 \mathrm{~m}^{2}$ grid spacing, and contains 1000 inlines and 500 crosslines. The maximum two-way travel time is 4 seconds. The 3-D seismic volume was recorded with SEG normal polarity, where the increase in acoustic impedance is shown as positive amplitude (black reflection). The frequency has a range of 7-55 Hz with a main frequency of 22-35 Hz. Overall, the resolution of the 3-D seismic dataset is good, but it is noisy in the upper section (from 0-250 ms TWT). The process to map and enhance fault interpretation includes data conditioning and seismic attribute analysis. The workflow used in the processing of data conditioning and seismic attribute analysis is illustrated in Fig. 3.

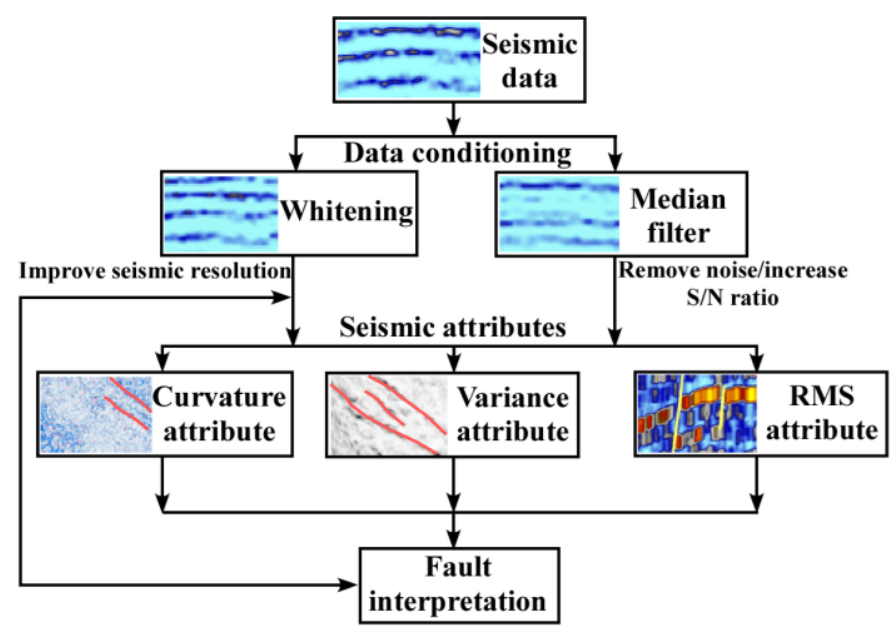

Fig. 3. Workflow used in the processing of data conditioning and seismic attribute analysis.

\section{A. Data conditioning}

Seismic attributes utilized in this study to delineate and enhance fault interpretation are sensitive to noise. Barnes (2016) reported that most seismic attributes extracted from seismic volume are only as good as the input quality. Acquisition related noise, random noise, and processing related noise do exist in the post-stack seismic data despite the careful noise removal process in the pre-stack stage. It is extremely crucial to eliminate the undesired signal resulted from data acquisition and processing and to enhance the seismic resolution before any seismic attribute analysis.

In this study, I utilized the data whitening method to enhance the resolution of the seismic data. The whitening method uses the information in low frequencies to predict and correct the high frequencies and enhance the resolution of the seismic data without adding noise to the original seismic dataset (Barnes, 2016). The median filter attribute was also applied to the post-stack data as a filter for the random noise. The two methods were applied at each time before the extraction of the attributes to improve the resolution of the seismic data (Fig. 4).

\section{B. Variance attribute}

Variance attribute measures the similarities between two or more seismic traces. A variance of " 1 " indicates that seismic reflections have inconsistent phase and amplitude and suggest a discontinuity in the seismic trace which may result from 


\section{International Journal of Engineering Applied Sciences and Technology, 2021 \\ Vol. 5, Issue 11, ISSN No. 2455-2143, Pages 53-56 \\ Published Online March 2021 in IJEAST (http://www.ijeast.com)}

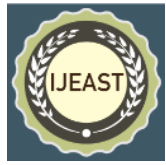

channel, faults, fracture, and lateral facies changes (Chopra and Marfurt, 2010; Dewett and Henza, 2016). The variance of " 0 " means that seismic reflections have consistent phase and amplitude. The variance attribute is utilized in this study to improve the interpretation of the major faults and delineate small fault zones. I extract the variance attribute at 650 and $745 \mathrm{~ms}$ which cut through the reservoir formation from the 3D seismic data (Fig. 6). It clearly helps to interpret major faults and minor fault and to some degree fracture zones.
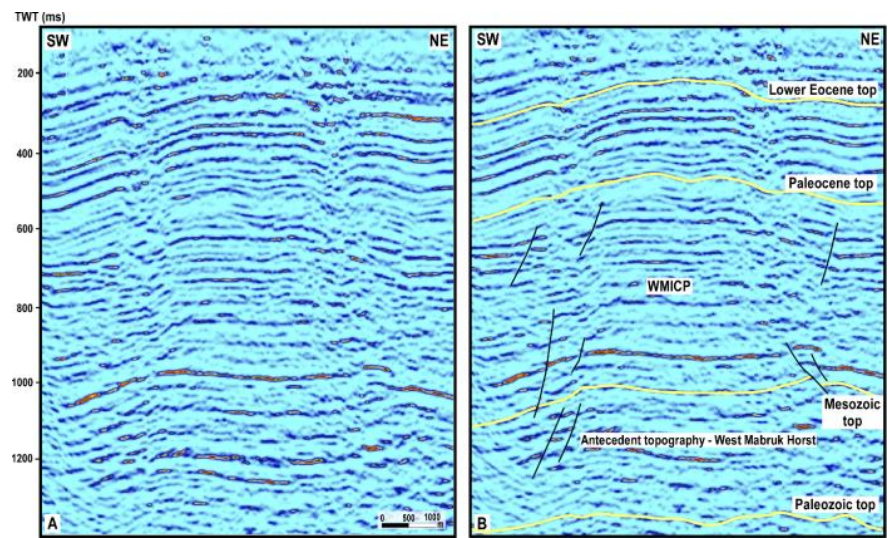

Fig. 4. (a) Original seismic inline 4600. (b) Same inline after application of data conditioning which includes whitening and median filter attributes. Note data quality and fault image are improved after applying the median filter and whitening compared to original seismic data.

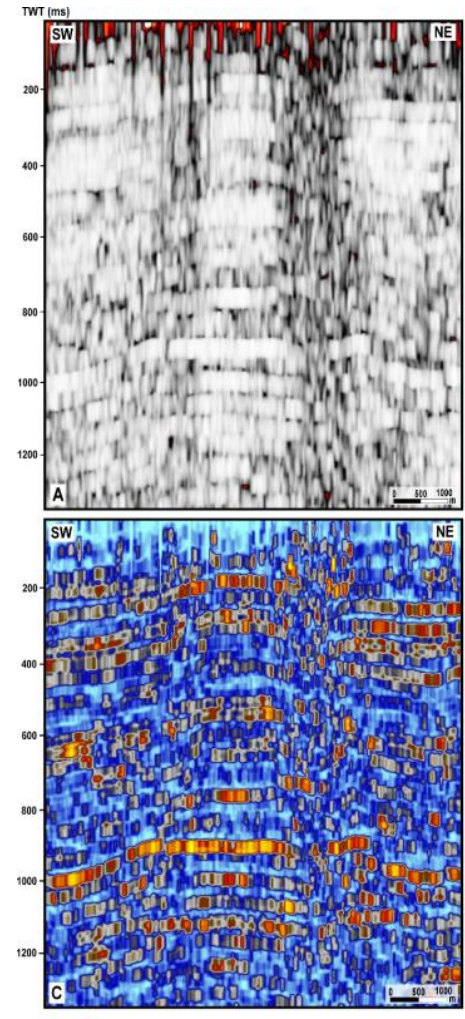

- NW-SE trending faults
Fig. 5. (a) Variance seismic inline 4665. (b) Same inline as in A showing the major faults and the presence of two reef buildups. The faults and reefs are seen as high variance which indicates high discontinuities. C) Root mean Square (RMS) seismic inline 4665. D) Same inline showing the faults identified in the west Mabruk isolated carbonate platforms in the NW Sirte Basin.

\section{Root mean square (RMS) amplitude}

Root mean square attribute resembles a smoother version of reflection strength. It is applied to reveal faults, channels, reef buildups, bright spots, and amplitude anomalies in the seismic data (Fig. 5c, d). It can also be used to highlight major lithology changes, compaction related effects (e.g., in marl and limestone) and unconformities. In this study, I used the root mean square attribute to reveal the major and minor faults developed in the west Mabruk Field along an isolated carbonate platform. Fig. 5c, d is seismic inline 4665 after applying the root mean square attribute. It clearly helps to interpret major and minor faults which are shown as discontinuities in the seismic reflections.
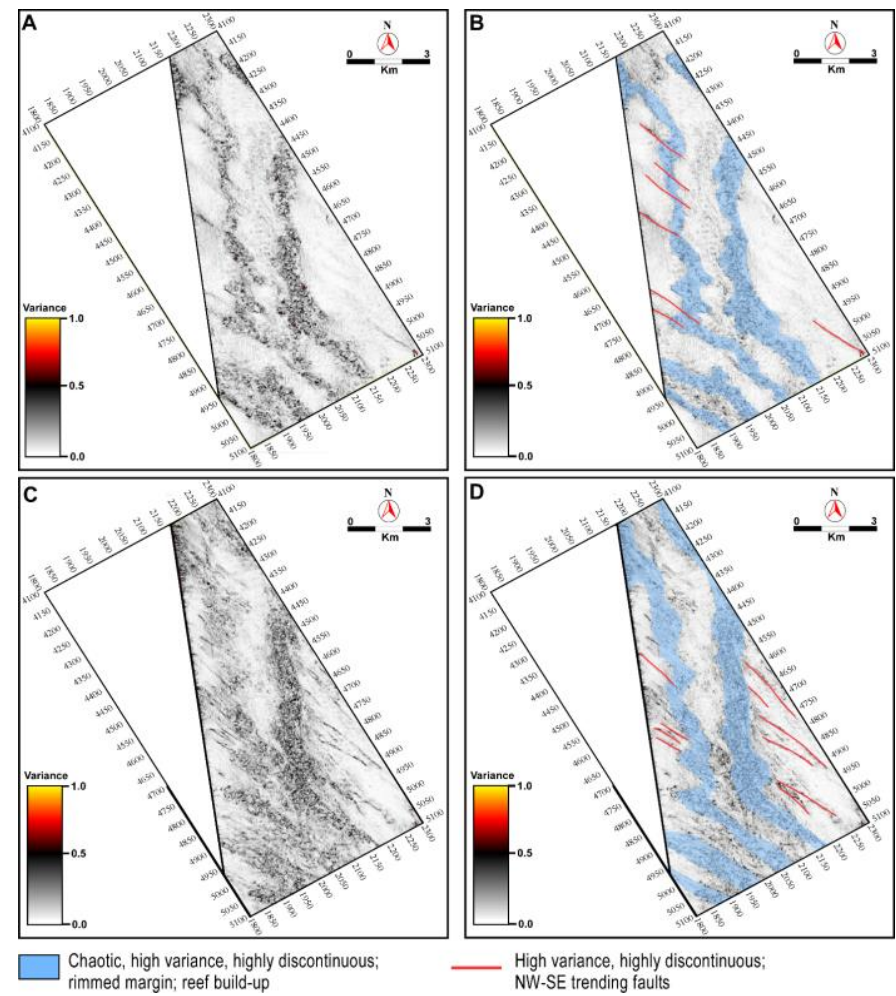

Fig. 6. (a) and (c) Variance time slices at 650 and $745 \mathrm{~ms}$, respectively. (b) and (d) Same slices showing the identified faults, which are seen as high variance anomalies. The shaded blue area is the reef buildup developed on the platform margins. 


\section{International Journal of Engineering Applied Sciences and Technology, 2021 \\ Vol. 5, Issue 11, ISSN No. 2455-2143, Pages 53-56 \\ Published Online March 2021 in IJEAST (http://www.ijeast.com)}

\section{Curvature attribute}

Curvature attribute describes how bent a surface is along a particular point. It is computed from the seismic data along both time slices and picked horizons. A curvature of "-0.4" means that the surface is bent downward, whereas a curvature of " 0.4 " indicates an upward bent of a surface. In this study, I use curvature attribute at $710 \mathrm{~ms}$ in order to better visualize the major and minor faults. The curvature slice determines both upthrown and downthrown of the fault blocks (Fig. 7). Using the attribute, I have detected several major and minor faults in the study area, which have a NW-SE trend (Fig. 7). Those identified faults cut through the Mabruk Formation which is the main reservoir in the northwest Sirte Basin. The better defined fault zones are extremely crucial for reservoir development, as it is dependent upon the natural fracture zones for its production.
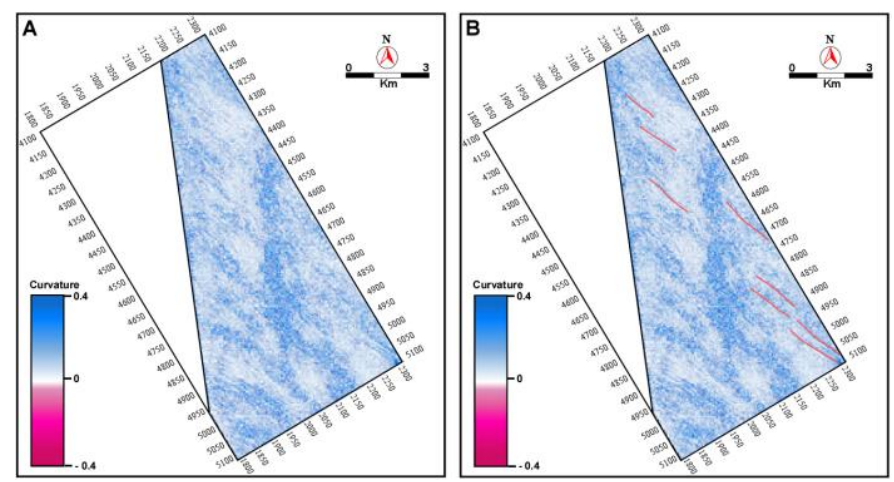

Fig. 7. (a) A curvature time slice at $710 \mathrm{~ms}$. (b). Same slice showing the NW-SE trending faults marked by the red lines.

\section{CONCLUSIONS}

Data conditioning is a useful tool to improve the quality of the seismic data and remove random noise. Data conditioning and seismic attributes help better understand the location, trend of major and minor faults. Spectral whitening and median filter significantly improved the quality of the data and increased the resolution of the seismic dataset, and better show edges and structural features. The integration of the variance, root mean square, and curvature seismic attributes has improved confidence in the seismic mapping of the major and minor faults which were difficult to delineate in the original seismic dataset. Variance attribute efficiently detected and enhanced the interpretation of faults of the lower and upper Paleocene reservoir formations in the study area. Root mean square attribute improved the detection of faults and discontinuities along horizons in the vertical seismic sections, while curvature attribute was efficient in delineating the upthrow and downthrow of the faults.

\section{REFERENCE}

[1] Abdalla, M. A., \& Yang, W. (2020). Clinoform Geometry and Sequence Stratigraphic Architecture of Lower and Middle Eocene Carbonate Prograding Sequences, Sirte Basin, North Central Libya (abs.): AAPG Annual Conference and Exhibition, Houston, Texas, 29 September-1 October, 2020.

[2] Ahlbrandt, T.S. (2002). The Sirte Basin province of LibyaSirte-Zelten total petroleum system. U.S. Geol. Surv. Bull. 1e26, 2202-F.

[3] Ambrose, G. (2000). The geology and hydrocarbon habitat of the Sarir Sandstone, SE Sirte Basin, Libya. Journal of Petroleum Geology, 23(2), 165-192.

[4] Barnes, A. E. (Ed.). (2016). Handbook of poststack seismic attributes. Society of Exploration Geophysicists.

[5] Chopra, S., \& Marfurt, K. J. (2010). Integration of coherence and volumetric curvature images. The Leading Edge, 29 (9), 1092-1107.

[6] Dewett, D. T., \& Henza, A. A. (2016). Spectral similarity fault enhancement. Interpretation, 4 (1), SB149-SB159.

[7] Gras, R., \& Thusu, B. (1998). Trap architecture of the early Cretaceous Sarir Sandstone in the eastern Sirt Basin, Libya. Geological Society, London, Special Publications, 132(1), 317-334.

[8] Guiraud, R., \& Bosworth, W. (1997). Senonian basin inversion and rejuvenation of rifting in Africa and Arabia: synthesis and implications to plate-scale tectonics. Tectonophysics, 282 (1-4), 39-82.

[9] Hallett, D. (2002), Petroleum geology of Libya: New York, Elsevier, 503p.

[10] Harding, T. P. (1984). Graben hydrocarbon occurrences and structural style. AAPG bulletin, 68 (3), 333-362.

[11] Mouzughi, A. J., \& Taleb, T. M. (1981). Tectonic Elements of Libya (1: 2,000,000). National Oil Corporation of Libya.

[12] Roohi, M. (1996). A geological view of source-reservoir relationships in the western Sirt Basin. The geology of Sirt Basin: Amsterdam, Elsevier, 2, 323-336. 